\title{
S-Enantiomer of the Antitubercular Compound S006-830 Complements Activity of Frontline TB Drugs and Targets Biogenesis of Mycobacterium tuberculosis Cell Envelope
}

Padam Singh, ${ }^{\dagger}$ Shashi Kant Kumar, ${ }^{\dagger}$ Vineet Kumar Maurya, ${ }^{\dagger}, \|$ Basant Kumar Mehta, ${ }^{\ddagger}$ Hafsa Ahmad, ${ }^{\S}$ Anil Kumar Dwivedi, ${ }^{\S}$ Vinita Chaturvedi, ${ }^{*}, \dagger$ Tejender S. Thakur, ${ }^{*}$, and Sudhir Sinha $\left.{ }^{*}, \dagger, \perp_{(}\right)$

${ }^{\dagger}$ Division of Biochemistry, ${ }^{\ddagger}$ Division of Molecular and Structural Biology, and ${ }^{\S}$ Division of Pharmaceutics, CSIR-Central Drug Research Institute, Sector-10, Jankipuram Extension, Lucknow 226031, India

"Department of Botany and Microbiology, HNB Garhwal University, Srinagar, Uttarakhand 246174, India

${ }^{\perp}$ Department of Clinical Immunology, SGPG Institute of Medical Sciences, Raebareli Road, Lucknow 226014, India

Supporting Information

ABSTRACT: A synthetic molecule S006-830, belonging to the class of thiophene-containing trisubstituted methanes, had shown good in vitro and in vivo bactericidal activity against drug-sensitive and drug-resistant Mycobacterium tuberculosis (Mtb). The molecule had also shown good druglike pharmacokinetic properties. However, S006-830 is a racemic mixture of two enantiomers, one of which could possess a better pharmacological profile than the other. We purified both the enantiomers on a chiral column and observed that S-enantiomer has a significantly higher inhibitory and cidal activity against Mtb than the R-enantiomer. Action of S-S006-830 was "synergistic" for rifampicin and "additive" for isoniazid and ethambutol. The combination of S-S006-830 and rifampicin produced $100 \%$ kill of $\mathrm{Mtb}$ within 8 days. In a chemical proteomics approach using matrix-bound compound to pull down its target

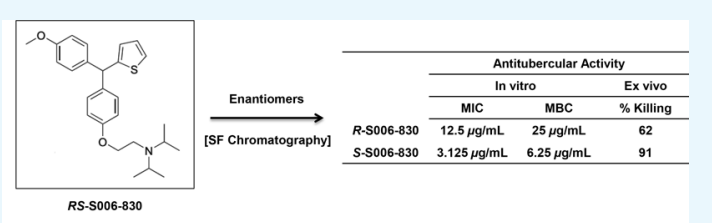
protein(s) from Mtb membrane, FabG4 ( $\beta$-ketoacyl CoA reductase, EC 1.1.1.100) emerged as the most likely target for $S$-S006-830. In target validation assays, the compound exhibited 2-fold higher inhibitory concentration for an Mtb construct overexpressing FabG4. In addition, it inhibited mycolic acid biosynthesis and formation of biofilms by Mtb. Molecular docking of S-S006-830 with FabG4 was consistent with the experimental data. These results support the development of $S$-S006-830 as a novel lead against tuberculosis.

\section{INTRODUCTION}

Tuberculosis $(\mathrm{TB})$ is a leading cause of death from infectious disease. In 2015, there were over 10 million new patients and nearly 2 million deaths due to TB. ${ }^{1}$ More alarmingly, there were over half a million new cases of multidrug-/rifampicinresistant (MDR/RR) TB. The treatment outcome data, on the other hand, show dismal success rates ( $83 \%$ for TB, $52 \%$ for MDR/RR TB, and $28 \%$ for XDR [extensively drug-resistant] TB). These figures reemphasize the need for new and potent anti-TB drugs. Several candidate drugs, including six "new chemical entities" are currently under clinical trials. ${ }^{1}$ Nonetheless, the process of developing a new drug is fraught with frequent setbacks. For instance, development of AZD5847 was terminated due to lack of anti-TB activity and that of TBA-354 had to be discontinued due to toxicity. ${ }^{1}$ Besides, the life of a successful antibiotic is cut short by the emergence of drugresistant microbes. It is therefore considered prudent to keep the drug pipeline awash with newer molecules.

In our ongoing campaign against $\mathrm{TB}$, we have previously reported on the synthesis and evaluation of novel thiophenecontaining trisubstituted methanes with antimycobacterial properties. $^{2-5}$ The identified lead S006-830 [diisopropyl-(2$\{4-[(R, S)$-(4-methoxy-phenyl)-thiophen-2-yl-methyl]-phenoxy\}-ethyl)-amine] showed an ex vivo efficacy comparable with isoniazid (INH), rifampicin (RIF), and pyrazinamide (PZA) and in vivo efficacy comparable with ethambutol (EMB) and PZA, with over 10-fold reduction in viable bacilli in the lungs of mice infected with Mycobacterium tuberculosis (Mtb). In addition, the compound also showed bactericidal activity against MDR, RR, and INHR (INH-resistant) clinical isolates of $\mathrm{Mtb}{ }^{4}$ In preclinical evaluations, the compound demonstrated good pharmacokinetic (PK) properties with rapid intestinal absorption. ${ }^{6,7}$ Peak plasma concentration was achieved at $<1 \mathrm{~h}$ post oral dose, the elimination half-life was $\sim 9 \mathrm{~h}$, the mean residence time was $\sim 11 \mathrm{~h}$, plasma protein binding was $\sim 60 \%$, and bioavailability was in the range of $45-$ $50 \%$. Cotreatment with S006-830 and verapamil (a P-gp inhibitor) in intestinal perfusion assay indicated that P-gp may

Received: September 1, 2017

Accepted: October 31, 2017

Published: November 30, 2017 
A
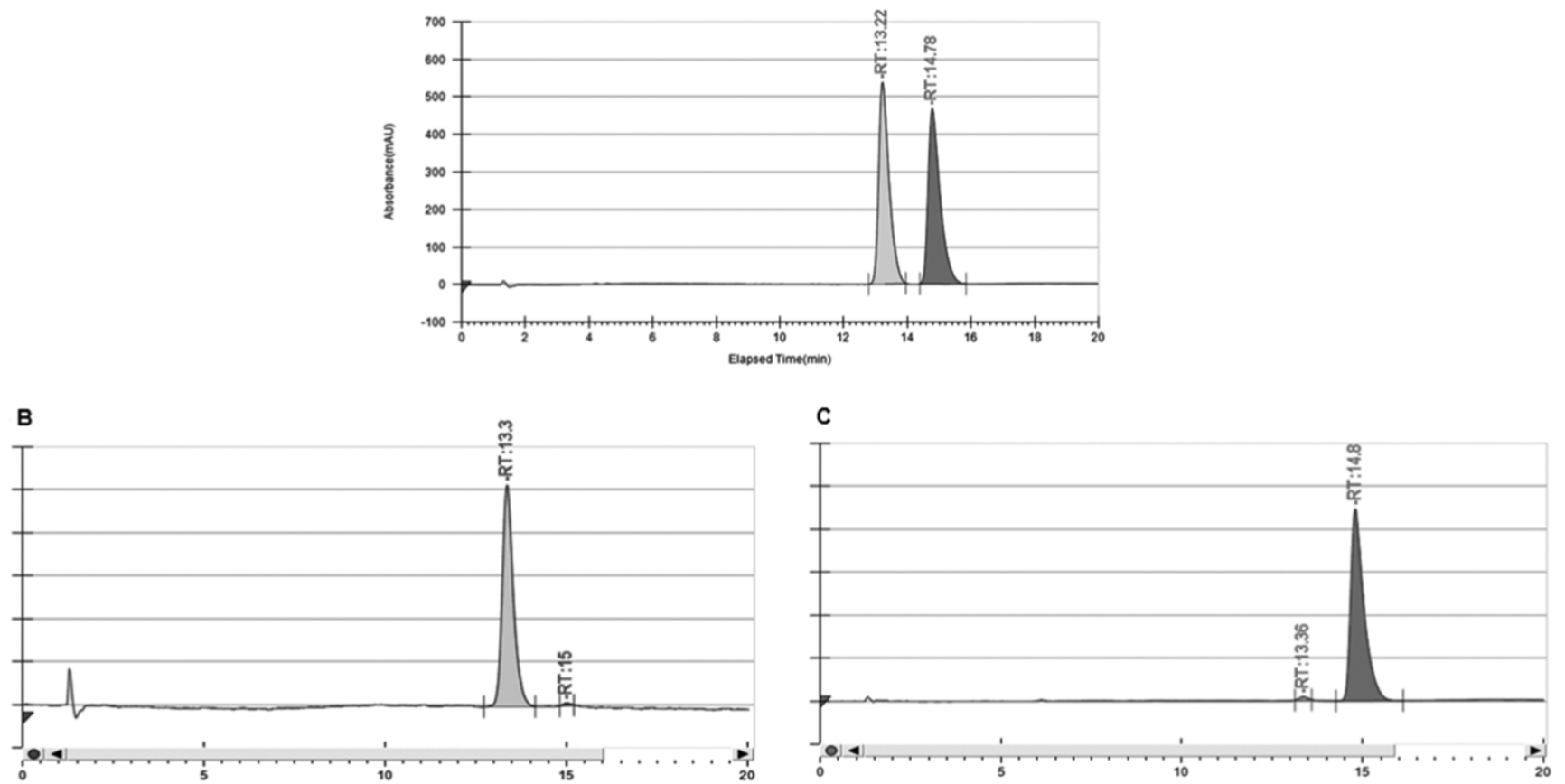

Figure 1. Racemate (A) and enantiomer (B, C) chromatograms of S006-830 using supercritical fluid chromatography on OJ-H column. The optimized isocratic conditions were methanol containing $0.5 \%$ isopropanol and flow rate of $2.5 \mathrm{~mL} / \mathrm{min}$. The outlet pressure was set to 120 bar and temperature was $35^{\circ} \mathrm{C}$. Detection wavelength was $233 \mathrm{~nm}$.

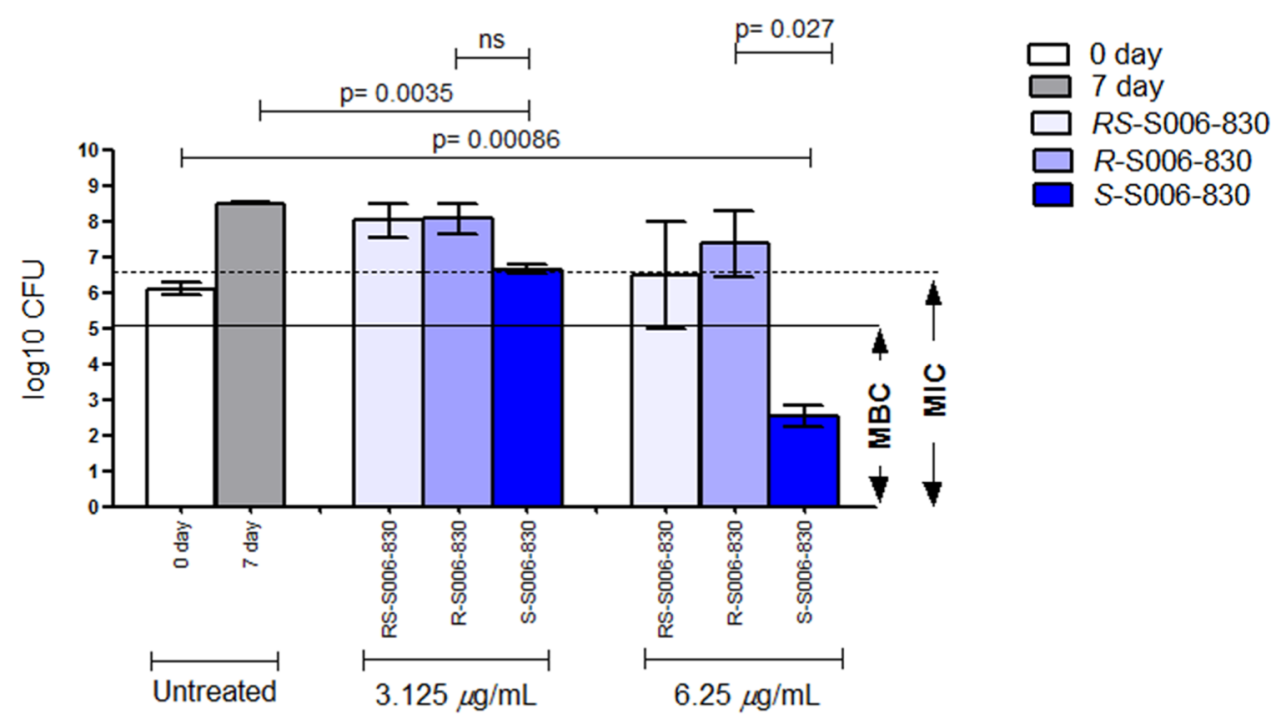

Figure 2. In vitro activity of S006-830 racemate (RS-S006-830) and its enantiomers against M. tuberculosis H37Ra (Mtb). Bacterial suspensions (inoculums) were exposed to the vehicle (untreated) or compounds (3.125 and $6.25 \mu \mathrm{g} / \mathrm{mL}$ ) for 7 days. The number of viable bacteria (cfu) was determined on days 0 (for bacterial counts in the inoculums) and 7 (for multiplication of bacilli in the inoculums in the presence of vehicle or compounds). Cutoff values for MIC (dotted line) and MBC (solid line) are shown. The S-enantiomer (S-S006-830) showed the highest antitubercular activity in terms of MIC as well as MBC. The corresponding $P$ values are shown (ns = not significant).

not be involved in the absorption of S006-830 and the compound may primarily be absorbed by paracellular transport. ${ }^{8}$ The compound was stable under various operating conditions. These PK parameters indicated rapid oral absorption, good tissue redistribution, and fast clearance of S006-830, which are the characteristics of a druglike molecule.

S006-830 has a chiral center (Supporting Information, Figure S1) and hence can exist in two enantiomeric forms: R and S. Enantiomers of a chiral drug are known to differ significantly in their pharmacological and/or PK properties. ${ }^{9}$ The significance of stereochemistry for drug activity has been studied in detail in the case of quinolones. Antibacterial activity of their Senantiomers is considerably higher than that of the $\mathrm{R}$ enantiomers or racemate, with 4- to 250-fold difference in the in vitro activity against both Gram-positive and Gram-negative bacteria. ${ }^{10}$ Among the new antitubercular drugs, S-enantiomer of PA-824 is nearly 100 -fold more active than the Renantiomer. ${ }^{11}$ In contrast, its R-enantiomer was more potent against Leishmania donovani. Bedaquiline has two chiral centers with four possible enantiomers, one of which $(R, S)$ is more 


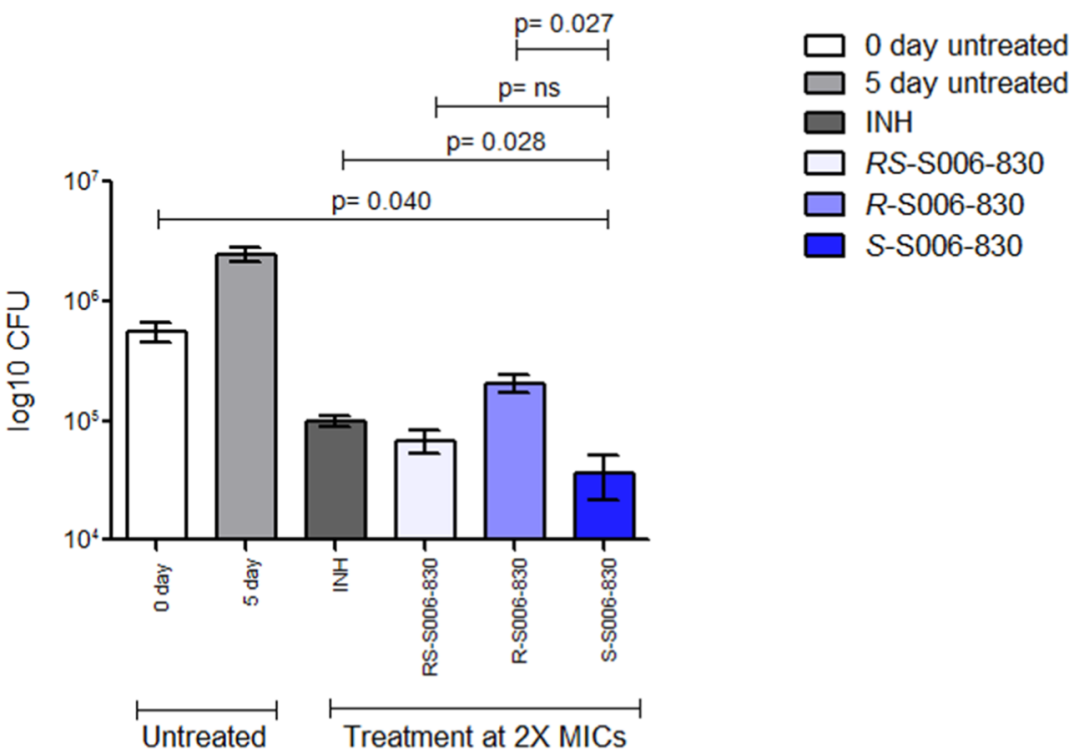

Figure 3. Ex vivo activities of the S006-830 and its enantiomers against Mtb within mouse macrophages. Macrophages were infected for $3 \mathrm{~h}$ and then exposed for 5 days to the standard drug (INH) or test compounds (RS-S006-830, R-S006-830, and S-S006-830) at their $2 \times$ MICs. The number of viable bacteria $(\mathrm{cfu})$ was determined on days 0 and 5 . Although all compounds and INH showed a bactericidal activity (i.e., reduction in day 0 counts), the activity of $S$-S006-830 was significantly higher than the R-enantiomer and INH. The corresponding $P$ values are shown (ns $=$ not significant).

Table 1. Interaction Profiles between S-S006-830 and Frontline TB Drugs Rifampicin, Isoniazid, and Ethambutol in Two-Drug Combination Checkerboard Assays

\begin{tabular}{|c|c|c|c|c|c|}
\hline \multirow[b]{2}{*}{ drug combination } & \multicolumn{2}{|c|}{ MIC against $\mathrm{Mtb}(\mu \mathrm{g} / \mathrm{mL})$} & \multirow[b]{2}{*}{ FIC of drugs in the combination } & \multirow[b]{2}{*}{$\mathrm{FICI}^{a}$} & \multirow[b]{2}{*}{ outcome } \\
\hline & alone & in combination & & & \\
\hline RIF & 0.00125 & 0.000312 & 0.25 & 0.5 & synergistic \\
\hline$S-S 006-830$ & 12.5 & 3.12 & 0.25 & & \\
\hline INH & 0.0625 & 0.0312 & 0.5 & 0.75 & additive \\
\hline$S-S 006-830$ & 12.5 & 3.12 & 0.25 & & \\
\hline EMB & 3.12 & 1.56 & 0.5 & 0.5625 & additive \\
\hline$S-S 006-830$ & 12.5 & 0.78 & 0.0625 & & \\
\hline
\end{tabular}

${ }^{a}$ FICI value $\leq 0.5$ indicates synergistic activity, FICI of $\geq 4.0$ indicates antagonistic activity, and values in between $\leq 4.0$ and $\geq 0.5$ indicate an additive interaction.

active than the rest. ${ }^{12}$ Benzothiazinone also has a chiral center, though both enantiomers are equipotent in vitro. ${ }^{13}$ Thus, an enantiopure drug may possess better pharmacologic and therapeutic profiles, along with simpler PK, than the racemate. Nonetheless, there are also instances where both enantiomers of a chiral drug contribute to its therapeutic effects and use of a single enantiomer may be less effective or even less safe. ${ }^{9}$

In this study, we have purified both the enantiomers of S006830 and compared their antitubercular activity vis-à-vis the racemate. Absolute configuration of the enantiomer showing higher activity was determined with the help of X-ray crystallography. The more active enantiomer was subjected to further evaluations aimed at unveiling its interactions with the first-line TB drugs, kill kinetics, and mechanism of action. To get an insight into the mechanism of action, we employed a chemical proteomics-based approach, ${ }^{14}$ which was complemented with the phenotypic approaches based on biosynthesis of cell wall mycolic acids ${ }^{15}$ and biofilm-forming property ${ }^{16}$ of Mtb. Finally, molecular modeling was employed to decipher the interactions between the compound and its putative target protein.

\section{RESULTS}

Isolation of S006-830 Enantiomers. Several recipes were tried to select the solvent system, which could provide best separation of both the enantiomers of S006-830 on a chiral column. Final separation was achieved with a mobile phase comprising $0.5 \%$ isopropanol in methanol. Retention times of the enantiomers were $\sim 13.22$ and $\sim 14.88 \mathrm{~min}$, and their optical purities were 99.2951 and $99.0467 \%$, respectively (Figure 1). The ratio of the enantiomers in $5006-830$ racemate was determined as 50.06:49.96.

Antitubercular Activity of the Enantiomers. Antitubercular activity of the S006-830 racemate has previously been reported by us. ${ }^{4}$ Therefore, we presently explored whether there was a difference in the potencies of its enantiomers. In drug-free cultures, the $\mathrm{Mtb}$ inoculums $\left(\sim 10^{6}\right.$ colony-forming units, cfu $)$ multiplied nearly $2.5 \operatorname{logs}\left(\sim 5 \times 10^{8} \mathrm{cfu}\right)$ over a period of 7 days (Figure 2). The S-enantiomer showed a minimum inhibitory concentration (MIC) of $3.12 \mu \mathrm{g} / \mathrm{mL}$, which was over 2-fold lower than the MIC of R-enantiomer $(12.5 \mu \mathrm{g} / \mathrm{mL})$ or the racemate $(\geq 6.25 \mu \mathrm{g} / \mathrm{mL})$. More importantly, only $S$-enantiomer showed a bactericidal activity (i.e., killing of the bacilli in inoculums) with a minimum bactericidal concentration (MBC) of $6.25 \mu \mathrm{g} / \mathrm{mL}$. The activity 
A

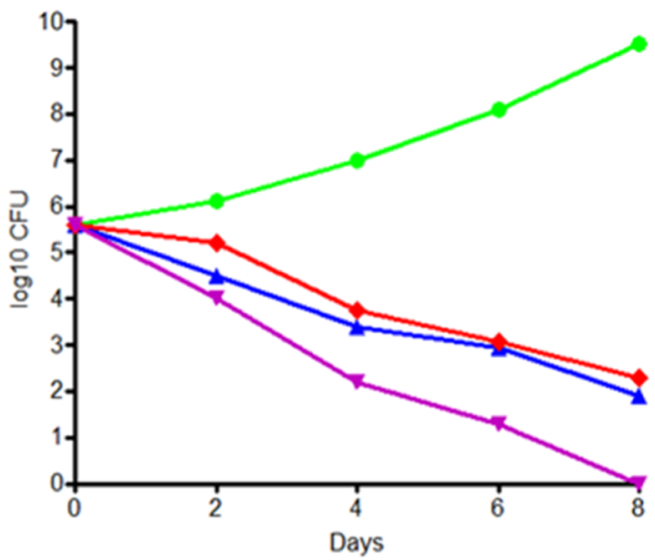

C

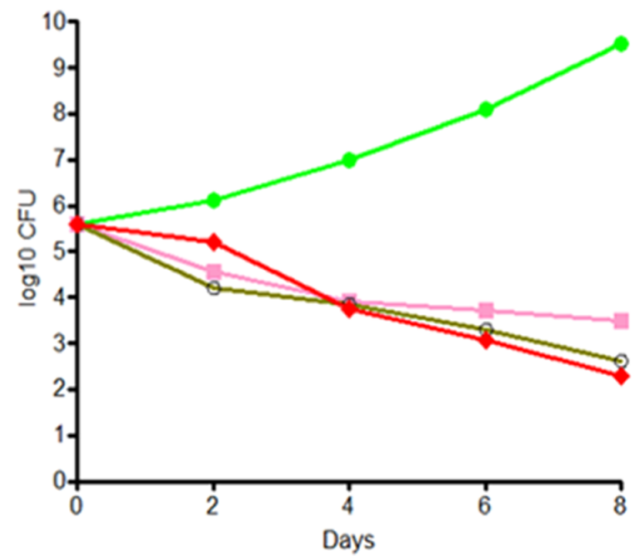

B

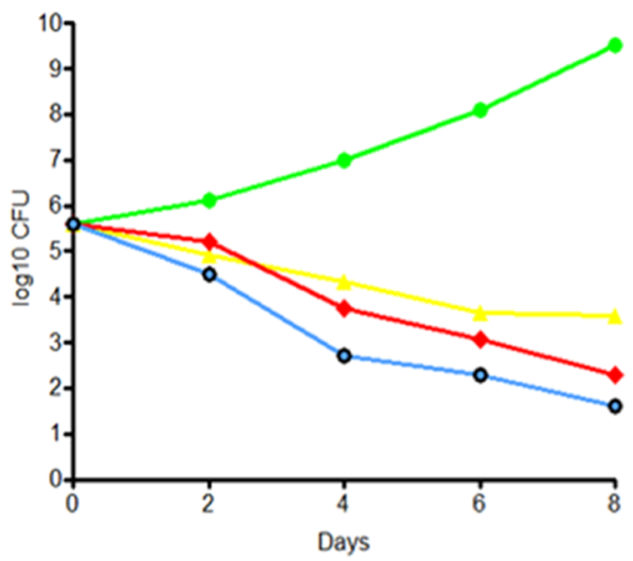

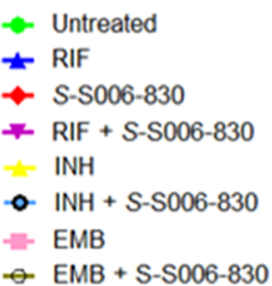

Figure 4. Time-kill kinetics of $S$-S006-830 and anti-TB drugs rifampicin, isoniazid, and ethambutol. Mtb inoculums were exposed to $2 \times$ MICs of RIF (A), INH (B), or EMB (C), either alone or in combination with S-S006-830. After 2, 4, 6, and 8 days of exposure, serial 10-fold dilutions of Mtb suspension from each set of experiment were plated on $\mathrm{MB}$ agar for cfu determinations.

of the R-enantiomer as well as racemate appeared to be bacteriostatic (i.e., inhibiting the multiplication of the bacilli in inoculums) within the used concentration range. These results demonstrated that S-S006-830 had a significantly higher antitubercular potency, in quantitative as well as qualitative terms, than $R$-S006-830 or the racemate (RS-S006-830).

We next compared the potencies of S- and R-enantiomers for killing of intracellular $\mathrm{Mtb}$ in the mouse macrophage model of infection. The infected macrophages were exposed to $2 \times$ MICs of the test compounds or standard drug isoniazid (INH). After 5 days of exposure, the S-enantiomer was able to kill $91 \%$ of the bacilli in inoculums (i.e., 0 day cfu) (Figure 3). This activity was significantly higher than the corresponding values for $\mathrm{R}$ enantiomer $(62 \%$ kill $)$ or INH $(80 \%$ kill $)$. None of the compounds were toxic for uninfected macrophages (data not shown).

The results of the in vitro and ex vivo antitubercular activities led us to select $S$-S006-830 as the lead compound for further investigations.

Interaction of S-S006-830 with Frontline TB Drugs. We determined the drug-drug interactions between S-S006830 and three frontline TB drugs in view of the fact that any new drug has to be a part of the combination therapy (so as to minimize the emergence of drug resistance). ${ }^{1}$ Interaction profiles of S-S006-830 with TB drugs are depicted in Table 1.
The combination of S-S006-830 with rifampicin (RIF) was found to be "synergistic" (fractional inhibitory concentration index or FICI $=0.5$ ), whereas the combinations with INH $($ FICI $=0.75)$ and ethambutol $($ EMB; FICI $=0.5625)$ were "additive" in nature. These results suggest that a combination of S-S006-830 with any of the three anti-TB drugs (particularly RIF) is likely to show higher efficacies at lower individual dosages.

The fact that observed "MIC" of S-S006-830 in this assay was higher than that determined by the MIC assay (above) needs to be considered. The checkerboard method is based on "no visible growth" of bacilli in inoculums over a period of 3 weeks. In that sense, MIC is in fact a measure of MBC. Further, the bacilli were cultured for extra 2 weeks (compared to just 1 week for MIC/MBC assays), which would give the residual viable bacilli a chance to grow, resulting in enhanced MIC/MBC.

To validate the synergistic or additive effects of S-S006-830 on frontline TB drugs, time-kill kinetics studies were performed. Time-kill kinetics of S-S006-830 alone or in combination with RIF, INH, or EMB is depicted in Figure 4. In drug-free cultures, $\mathrm{Mtb}$ in the inoculums $\left(5 \times 10^{5} \mathrm{cfu}\right)$ multiplied 4 logs (to approximately $5 \times 10^{9} \mathrm{cfu}$ ) in a span of 8 days. Within the same time frame, the combination $(2 \times$ MIC each) of S-S006-830 and RIF produced $100 \%$ kill of the bacilli in inoculums. Importantly, neither drug alone could achieve 


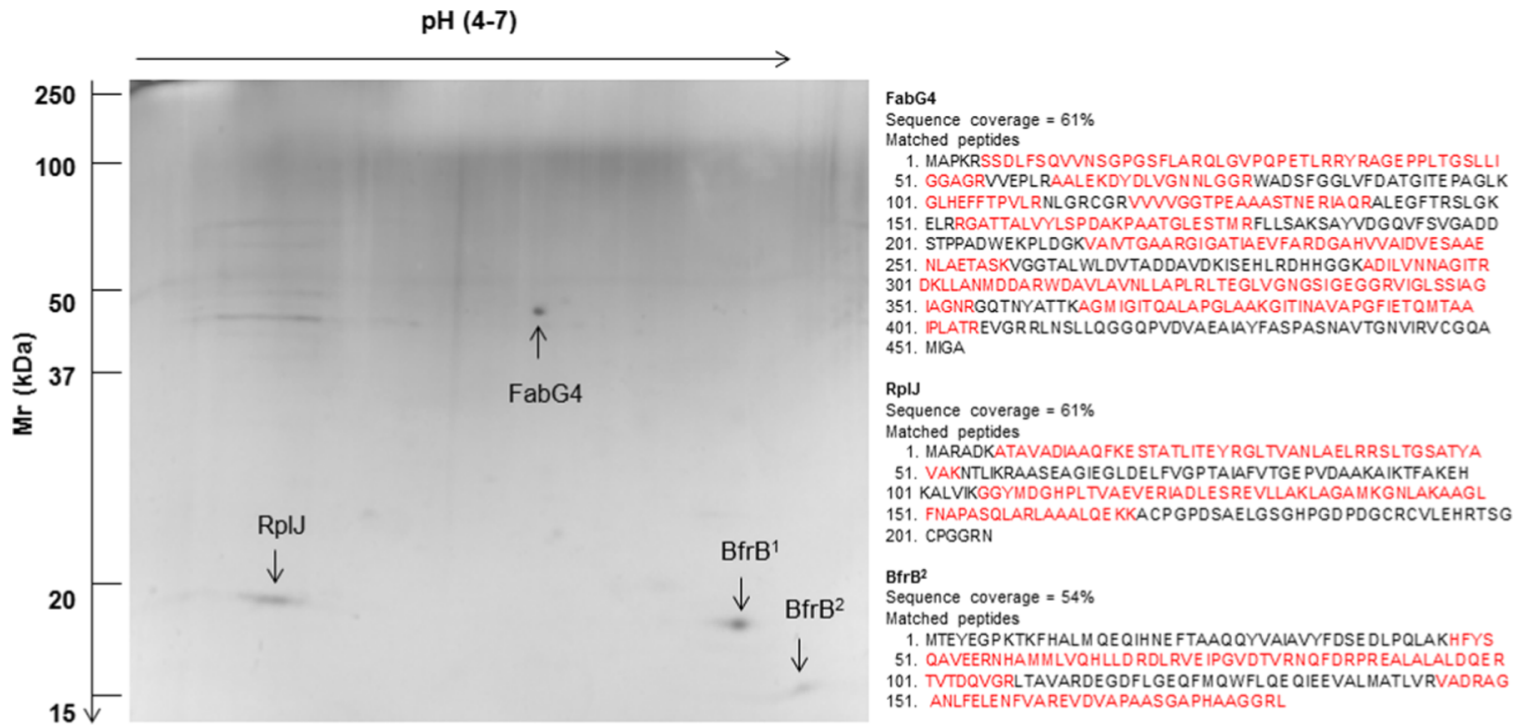

Figure 5. Identification of Mtb proteins targeted by S-S006-830. The membrane proteins of Mtb (solubilized by CHAPS) were incubated overnight with $S$-S006-830 linked to a matrix (agarose beads). Affinity matrix-bound proteins were resolved by 2-DE, digested with trypsin, and identified by LC-MS-MS. The identified proteins were FabG4, RplJ, and BfrB (appearing in two spots). Complete as well as covered (in red) sequences of these proteins are also shown.

this level of efficacy. However, the combination of S-S006-830 with INH showed only a marginal improvement and that with EMB showed no improvement over the kill achieved by each drug individually. These results suggest that the combination of S-S006-830 with RIF was most efficacious, followed by the combinations with INH and EMB.

Identification of the Target(s) of S-S006-830. By Chemical Proteomics. Chemical proteomics is the method of choice for the identification of the putative target(s) of a drug in an unbiased manner. ${ }^{14}$ The method combines drug-affinity chromatography and high-resolution mass spectrometry for the identification of proteins. To pursue this approach, S-S006-830 was coupled with DADPA-activated agarose beads (Supporting Information, Figure S2) and the membrane proteins of $\mathrm{Mtb}$, solubilized with a nonionic detergent (CHAPS), were incubated with bead-bound S-S006-830. The beads were washed extensively to remove all loosely or nonspecifically bound proteins. To ensure this, each wash was monitored by sodium dodecyl sulfate-polyacrylamide gel electrophoresis (SDS-PAGE) (Supporting Information, Figure S3).

Two-dimensional gel electrophoresis (2-DE) of the affinity matrix-bound proteins revealed four spots (Figure 5). Peptidemass fingerprinting of these spots led to the identification of corresponding proteins as FabG4 (sequence coverage, 61\%), RplJ (sequence coverage, 61\%), and BfrB (in two spots with sequence coverage of 26 and 54\%). The sequences covered by the tryptic peptides in each case are depicted in Figure 5.

In addition to the membrane, we also incubated cytosolic proteins of Mtb with bead-linked S-S006-830. However, 2-DE analysis of the washed beads in this case did not show any protein spot, suggesting that the putative target(s) were enriched in the Mtb membrane. This observation is consistent with the reported membrane association of the targets of most antitubercular compounds. ${ }^{1}$

By Comparing Membrane Proteome of the Wild-Type and S-S006-830-Resistant Mtb. This approach was pursued as a supplement to chemical proteomics. It is based on the premise that the target protein $(s)$ might get overexpressed by the bacilli which are grown under drug pressure. ${ }^{17}$ Drug sensitivity profiles of the wild-type $\mathrm{Mtb}$ and $\mathrm{Mtb}$ made resistant to $S$ S006-830 by culturing under drug pressure are shown in the Supporting Information, Table S3. The resistant bacilli showed compound-specific resistance while remaining sensitive to RIF, $\mathrm{INH}$, and EMB.

Comparison of the 2-DE patterns of membrane proteins of the wild-type and S-S006-830-resistant Mtb (Supporting Information, Figure S4) revealed the proteins that were overexpressed by the resistant bacilli. Consistent with the results of chemical proteomics, FabG4 was identified as one of the three overexpressed proteins (Supporting Information, Table S4). The other two proteins were considered as inconsequential because they did not figure among the proteins pulled down by drug-affinity matrix.

The pull-down of FabG4 by drug-affinity beads along with its overexpression by S-S006-830-resistant Mtb suggested that FabG4 was the most likely target for the compound. We therefore went on to validate this probability.

Validation of FabG4 as the Target for S-S006-830. Effect of fabG4 Overexpression on the Sensitivity of Mtb for the Compound. Overexpression of the target in a drugsensitive microbe is expected to push upward the MIC of a drug. ${ }^{17}$ We prepared a construct of Mtb overexpressing FabG4 (Supporting Information, Figure S5) and used it in the MIC assays. The results (Supporting Information, Table S5) show over 2-fold increase in the MIC of $S$-S006-830 $(=6.25 \mu \mathrm{g} / \mathrm{mL})$ against the construct, compared with its MIC against the vector control or parental Mtb strain $(=3.125 \mu \mathrm{g} / \mathrm{mL})$. On the other hand, the susceptibility of the construct for RIF, INH, and EMB remained unchanged. These results supported the probability of FabG4 being the target of S-S006-830.

Effect on the Synthesis of Mycolic Acids. FabG4 belongs to the family of $\beta$ ketoacyl reductases and utilizes $\mathrm{NADH}$ to reduce 3-ketoacetyl $\mathrm{CoA}$ to 3-hydroxyacetyl $\mathrm{CoA}$, which is involved in the type-II fatty acid synthase (FAS-II) pathway. ${ }^{18}$ FAS-II in Mtb generates mycolic acids, which are vital components of the cell envelope. ${ }^{15}$ We therefore decided to determine the effect of S-S006-830 on the synthesis of mycolic acids. Mtb cultures were treated with S-S006-830 or INH prior 

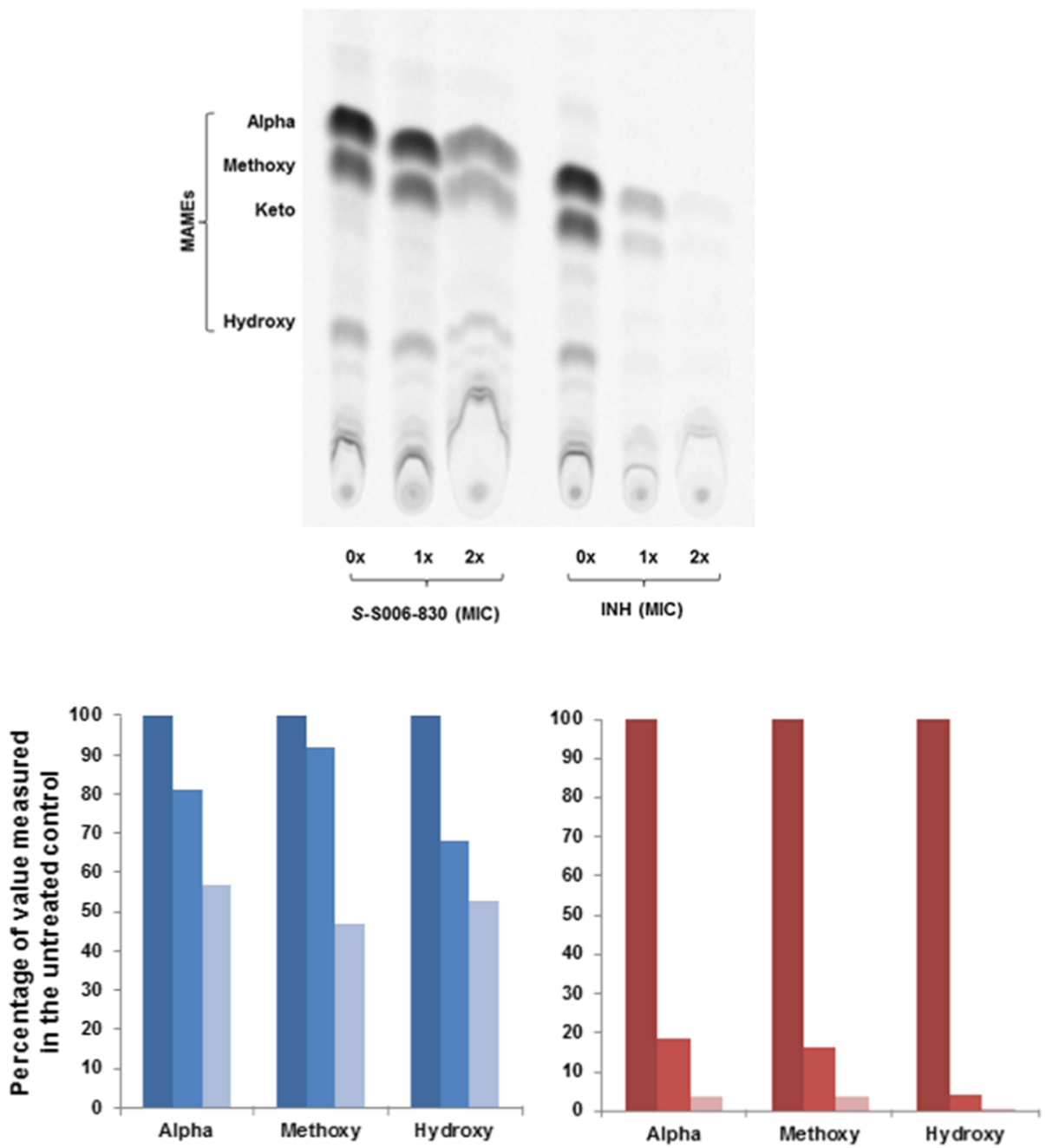

=S-S006-830 0x MC

= S-S006-830 1x MC

=S-S006-830 2x MC

$=$ INH OX MIC

$=$ INH 1X MIC

$=\mathrm{INH} 2 \times \mathrm{MIC}$

Figure 6. Reduction in the synthesis of mycolic acids by S-S006-830. Top panel shows TLC of $\left[{ }^{14} \mathrm{C}\right]$-labeled mycolic acid methyl esters (MAMEs) of $\mathrm{Mtb}$ treated with $1 \times$ and $2 \times$ MICs of S-S006-830 or INH. Equal counts were loaded and chromatogram was developed with hexane/ethyl acetate $(19: 1, \mathrm{v} / \mathrm{v}$, two runs) as solvent system. The amount of radioactivity incorporated in the products of interest was semiquantified using a phosphorimager, and the results (expressed as a percentage of the value measured in the untreated control, $0 \times$ MICs) are presented as histograms (bottom panels).

to metabolic labeling of the bacilli with $\left[{ }^{14} \mathrm{C}\right]$ acetate. Radiolabeled lipids, extracted from bacterial cells, were analyzed by thin-layer chromatography (TLC). As shown in Figure 6, treatment with $S$-S006-830 suppressed the synthesis of all mycolic acid methyl esters (MAMEs) in a dose-dependent manner. However, the inhibition was not as steep as that caused by INH, which is a highly potent inhibitor of the mycolic acid biosynthesis. As per applied protocol, only a short exposure (15 h) of 1-2 MICs of the drug/compound was given to high inoculums $\left(\sim 10^{10} \mathrm{cfu}\right)$ of $\mathrm{Mtb}$, which did not affect the bacterial cell viability significantly (data not shown).

Inhibition of Biofilm Formation. In its growth medium, Mtb typically forms biofilms at the liquid-air interface. Bacteria within the biofilm stay embedded in a complex extracellular matrix (ECM). In case of Mtb, mycolic acids and some polyketide synthase1 (PKS-1)-generated unknown lipids have been described as the components of ECM. ${ }^{16}$ FabG4 is overexpressed by the $\mathrm{Mtb}$ in biofilms ${ }^{19}$ and hence could be involved in the biosynthesis of ECM lipids. We therefore determined the effect of S-S006-830 on the formation of biofilm by Mtb. As shown in Supporting Information, Figure S6, the compound inhibited biofilm formation by the wild-type bacilli in a dose-dependent manner. There was a marked inhibition at $1 \times$ and complete inhibition at $2 \times$ MIC. On the other hand, the compound did not inhibit biofilm formation by the S-S006-830-resistant Mtb. These results indicated once again that $S$-S006-830 could be acting through inhibition of the cell wall lipids, including mycolic acids.

Crystal Structure of S-S006-830 and Computational Studies. The binding of a drug to its target protein involves interactions between hydrogen bonding functionalities of the drug and their complementary sites on the target. Such interactions may have considerable steric constraints, for example, in terms of interatomic distance and steric bulk.

Crystal Structure. The stereochemistry of the lead enantiomer was assigned to as S-S006-830 with the help of $\mathrm{X}$-ray crystallography. Absolute structure in this case was determined using 2121 Friedel pairs (Bijvoet pairs coverage, $\sim 96 \%$ ) with a Flack parameter ${ }^{20}$ value of $0.07(3)$. Crystal structure showed disorder in the thiophene ring of the molecule and was refined further with sulfur atom disordered over two positions with a 0.86:0.14 occupancy ratio. Final refinements were performed using TWIN/BASF instructions to account for a possible inversion twin. ORTEP showing the asymmetric unit 
A

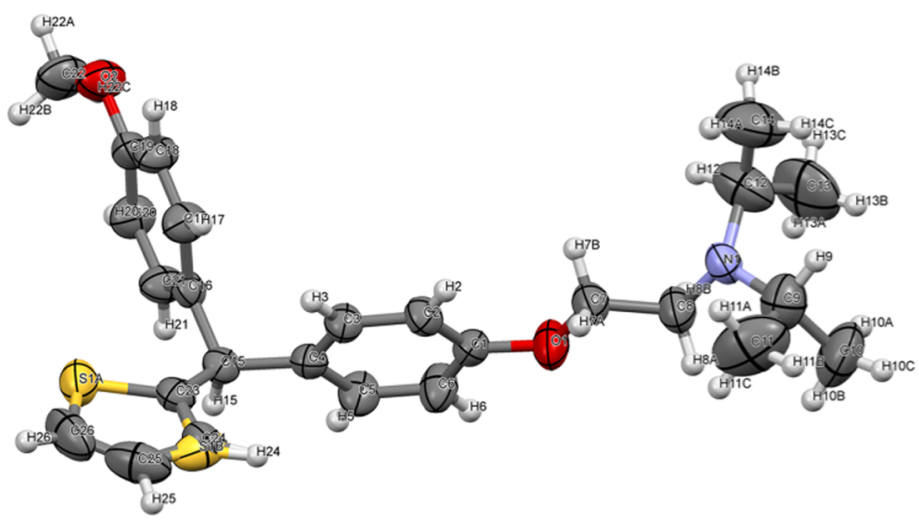

B

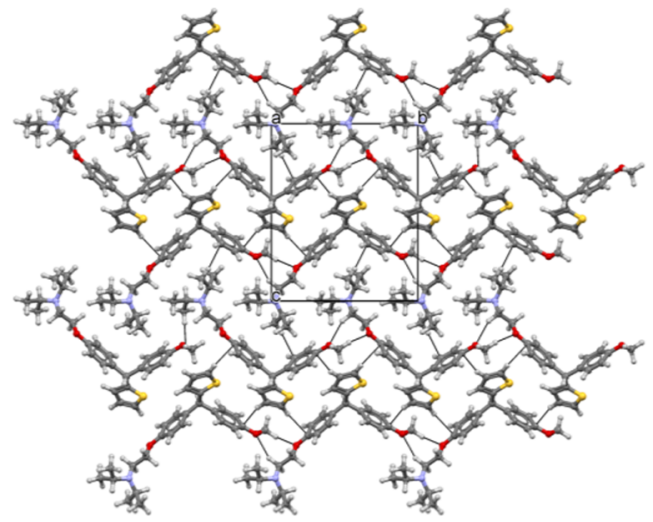

C

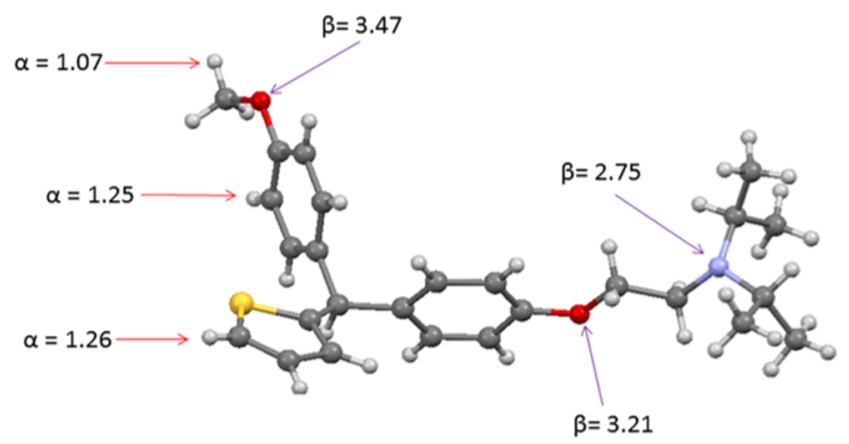

D

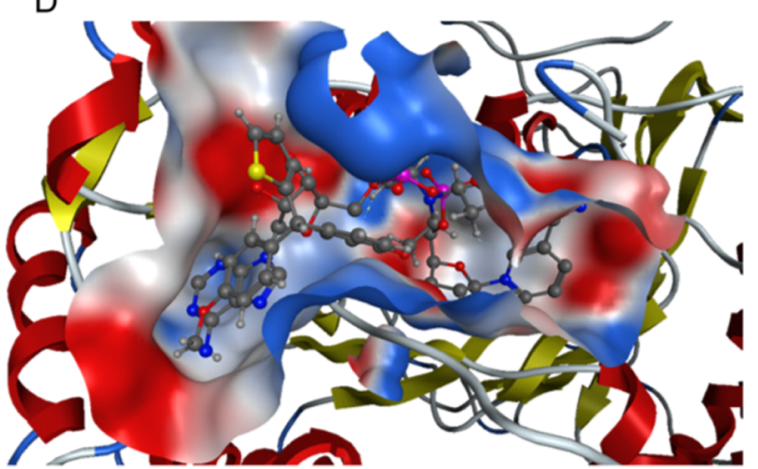

Figure 7. (A) ORTEP showing the asymmetric unit of the crystal structure of S-S006-830. Thermal ellipsoids for non-H-atoms are drawn at 50\% probability. (B) Molecular packing in the crystal structure of S-S006-830 (disordered atoms are not shown for clarity). (C) Electrophilic $(\alpha)$ and nucleophilic $(\beta)$ interaction sites marked on S-S006-830. (D) Active site overlay of NAD ${ }^{+}$and S-S006-830 bound to Mtb FabG4.

of the crystal structure of S-S006-830 is depicted in Figure 7a. The pendant thiophene ring and $\mathrm{N}, \mathrm{N}$-diethylamino group from either side of the chains form interlocked zipper-type motif in the crystal, stabilized by weak $\mathrm{C}-\mathrm{H} \cdots \pi$ interactions (Figure $7 \mathrm{~b})$. The compound contains two alkoxy O-atoms, one amino $\mathrm{N}$-atom, and heterocyclic S-atom that can serve as potential hydrogen bond acceptors. Besides this, thiophene and phenyl rings can act as $\pi$ acceptors. Local maxima and minima on the molecular electrostatic potential surface were used for the identification of potential interaction sites present on S-S006830 that may be involved in the interaction with the target protein. The computed values for hydrogen bond interaction parameters $(\alpha, \beta)$ show highest values for the $\beta$-parameter on the two alkoxy $\mathrm{O}$-atoms indicative of a preferential hydrogen bond acceptor site. The thiophene and phenyl $\mathrm{C}-\mathrm{H}$ groups possess the most electrophilic sites that can provide weak $\mathrm{C}-$ $\mathrm{H} \cdots \mathrm{O} / \mathrm{C}-\mathrm{H} \cdots \pi$-type interactions (Figure $7 \mathrm{c}$ ). Involvement of these interactions was also seen in the crystal. The S-S006-830 molecules arranged in a zigzag chain were held by weak $\mathrm{C}-\mathrm{H} \cdot \cdots$ $\mathrm{O}$ interactions formed between the two alkoxy groups in the crystal (Supporting Information, Table S6).

Molecular Docking. Active site analysis resulted in the identification of two plausible ligand-binding pockets on FabG4 protein (Supporting Information, Figure S7). The top-scored site-1 is the larger pocket that spans the $\mathrm{NAD}^{+}$and hexanoyl$\mathrm{CoA}$ binding region of the C-terminal domain of FabG4 complex. Site-2, on the other hand, corresponds to a smaller pocket located in the $\mathrm{N}$-terminal domain (Supporting
Information, Table S7). Molecular docking studies were performed on both of the pockets to ascertain the most probable binding region for S-S006-830. Due to the large pocket size of site-1, the docking of S006-830 was performed by considering the $\mathrm{NAD}^{+}$and hexanoyl-CoA binding regions separately in two sets for an efficient sampling. Additionally, a comparative docking with $R$-S006-830 onto these pockets was performed to assess the binding preference of the two enantiomers for FabG4. Both enantiomers showed a preference for site-1 to site-2 (Supporting Information, Figures S8 and S9) as reflected by higher dock scores (Supporting Information, Tables S8 and S9). Among the two, the S-enantiomer showed a slightly higher binding free-energy score $(-8.09)$ than Renantiomer (-7.99). Docking shows a preferential binding of S-S006-830 near the $\mathrm{NAD}^{+}$binding region (Figure $7 \mathrm{~d}$ ). Topscored docking pose shows a weak $\mathrm{C}-\mathrm{H} \cdots \pi$ interaction with VAL245 (Supporting Information, Table S8).

\section{DISCUSSION}

In our earlier studies, the S006-830 racemate had shown an impressive bactericidal activity against drug-sensitive as well as drug-resistant $\mathrm{Mtb} .{ }^{4}$ It had produced over 10 -fold reduction in viable bacterial counts in the lungs of mice infected with $\mathrm{Mtb}$, an activity comparable with some of the candidate antitubercular drugs currently under trial. ${ }^{1}$ This in vivo activity was attained despite relatively high (compared with other drug candidates) MIC and MBC of the compound, owing perhaps to its good oral bioavailability. ${ }^{7,8}$ As the pharmacokinetic profiles 
of enantiomers of a drug may differ markedly from the racemate, ${ }^{9}$ evaluation of the enantiomers of S006-830 presented a possibility for reduction in its effective dose, which could lead to improvement in its efficacy and safety profiles.

Both the enantiomers ( $R$-S006-830 and S-S006-830) could be isolated, each with over $99 \%$ purity, from the racemate (RSS006-830) by supercritical fluid chromatography. MIC of $S$ S006-830 for Mtb was $<50 \%$ of the MICs of R-S006-830 or RSS006-830. More importantly, at lower concentrations, the action of the $S$-enantiomer was bactericidal, whereas it was bacteriostatic in cases of R-enantiomer or the racemate. Against intracellular Mtb also, the bactericidal activity of S-enantiomer was significantly higher. These observations formed the basis for choosing S-enantiomer as the lead compound, and its absolute configuration could be assigned with the help of X-ray crystallography. In drug-drug interaction studies, the most noteworthy observation was the synergy between S-S006-830 and rifampicin. Although neither could kill $100 \%$ of the bacilli on their own, their combination could do so. Remarkably, the effective dose of $S$-S006-830 in this combination was approximately $1 / 4$ of the dose if used alone. Therefore, as a component of "combination therapy", S-S006-830 is likely to show better efficacy as well as safety profiles.

In the chemical proteomics-based approach for target identification, ${ }^{14}$ three membrane-associated proteins of Mtb, BfrB, RplJ, and FabG4, were pulled down by $S$-S006-830. The used protocol for linking the compound to affinity matrix was such that its putative pharmacophore ${ }^{4,5}$ remained free to interact with target protein(s). Membrane association of all three proteins has previously been demonstrated by $\mathrm{us}^{21}$ and others. ${ }^{22}$ BfrB is a ferritin-like protein and exists as an assembly of 24 monomers with a central cavity to store ferric iron, which is transported into the cytoplasm of $\mathrm{Mtb}$ by the cell-envelopeassociated siderophore mycobactins. ${ }^{23}$ The $50 \mathrm{~S}$ ribosomal protein RplJ (L10) is involved in translation mechanisms and remains complexed with other ribosomal proteins on the inner surface of Mtb cell membrane. ${ }^{21,24}$ The third pulled-down protein FabG4 belongs to the family of FabGs ( $\beta$-ketoacyl CoA reductases), which catalyze the second step of FAS-II pathway, where $\mathrm{NAD}(\mathrm{P}) \mathrm{H}$ is utilized to reduce $\beta$-oxoacyl-ACP to $\beta$ hydroxyacyl-ACP. ${ }^{18}$ In Mtb, FAS-II produces mycolic acids, which are vital components of the cell envelope. ${ }^{15}$

A possible limitation of chemical proteomics is that pulldown of a protein depends on its affinity as well as abundance, due to which some high-abundance proteins with low affinity (for the compound) may also get pulled down. Due to this, high-affinity interactions with low-abundance proteins are considered as most relevant for target identification. ${ }^{14}$ Although $\mathrm{BfrB}$ and RplJ fall into top 5\% of the high-abundance mycobacterial proteins, FabG1 (data for FabG4 are currently unavailable) has a relatively low abundance, falling within top $10 \%$ of the proteome. ${ }^{25}$ Moreover, expression of BfrB may be induced nonspecifically by hypoxia ${ }^{26}$ or certain antibiotics, such as aminoglycosides. ${ }^{27}$ Similarly, ribosomal proteins may also get overexpressed by stress. $^{24}$ These results and considerations prompted us to converge on FabG4 as the putative target for $S$ S006-830. This convergence found support from the comparative proteome analysis of compound-sensitive and compound-resistant Mtb. FabG4, and not BfrB or RplJ, was found overexpressed in the membrane of the resistant bacilli.

Assays to validate FabG4 as a target for S-S006-830 addressed the functional implications of binding of compound to the target. To begin with, we saw a 2 -fold increase in the MIC of S-S006-830 for an Mtb construct overexpressing FabG4. Second, in view of its role in FAS-II pathway, binding of FabG4 to the compound was expected to curtail the production of mycolic acids. We observed a dose-dependent reduction in all species of mycolic acids, although the reduction was not as steep as that caused by INH. This difference in activity could be reconciled with the fact that INH targets multiple enzymes of the FAS-II pathway, including InhA, which is crucial for the final step of mycolic acid synthesis. ${ }^{28}$ The third set of validation experiments assessed the biofilm-forming ability of $\mathrm{Mtb}$ because FabG4 is specifically overexpressed by Mtb in the biofilms. ${ }^{19}$ Prevention of biofilm formation by S-S006-830 suggested that inhibition of FabG4 could cause a paucity of lipids (including mycolic acids) in the extracellular matrix required for biofilm formation. ${ }^{16}$ Results of molecular docking experiments also validated FabG4 as the target for the compound. In addition, the difference in binding free-energy scores of the two enantiomers was consistent with the observed higher antitubercular activity of S-S006-830.

For several reasons, FabG4 qualifies as a unique drug target against TB. Mtb genome has five fabG genes, but only two of them (G1 and G4) are conserved across the mycobacterial species, including the leprosy pathogen M. leprae. ${ }^{29} \mathrm{~A}$ distinctive feature of FabG4 is that it falls in the category of "high molecular weight" FabGs (molecular weight, $46.83 \mathrm{kDa}$ ), whereas the other four FabGs are of "low molecular weight" (mol. wt. ranging from 27.14 to $25.67 \mathrm{kDa}$ ). In addition, FabG4 is highly specific for NADH as a cofactor, whereas the lowmolecular-weight FabGs utilize NADPH. In mycobacteria, FabG4 belongs to an operon possibly involved in a nonconventional processing of fatty acids. ${ }^{30}$ Indeed, functional complementation in the yeast has demonstrated that FabG4 can participate in fatty acid biosynthesis. ${ }^{31}$ However, there is scanty data on the role of FabG4 in processing of fatty acids, as most available studies are focused on FabG1. ${ }^{32}$ There are also reasons to believe that FabG4 could serve as a target against latent $\mathrm{TB}$ infection (LTBI) as it is expressed in the lungs of guinea pigs during the chronic phase of infection. ${ }^{33}$ Besides, FabG4 remains active in the acidic $\mathrm{pH}$ range $5.5-6.0^{18}$ representing the milieu of the phagolysosome, the intracellular niche of Mtb during latent or chronic infections. ${ }^{34}$ Hence, by targeting FabG4, S-S006-830 may also act against LTBI. In an earlier report, we have shown that S006-830 can cure mice of an acute as well as persistent infection with M. fortuitum. ${ }^{3}$

In conclusion, our study demonstrates that the S-enantiomer is the most active species of the antitubercular compound S006830. It exhibited a synergistic or additive activity with the frontline TB drugs. The target identification and validation assays pointed to FabG4 as the most likely target for S-S006830. Nonetheless, the simplified view of "one drug, one target" does not hold true anymore, and the concept of "polypharmacology", that is, drugs may need to target several proteins for their effectiveness, is gaining ground. ${ }^{35}$ In this respect, a possible limitation of this study could be that we have not validated the other two proteins (BfrB and RplJ) pulled down by the compound as its additional targets. This could be a subject for future investigation as we make more progress toward developing S-S006-830 as a novel lead against tuberculosis. 


\section{EXPERIMENTAL SECTION}

Materials. Details of materials are given in the Supporting Information, Table S1.

Mycobacteria. The culture of Mycobacterium tuberculosis H37Ra (Mtb) was maintained on Lowenstein-Jensen medium. Working stocks were prepared by subculturing the bacilli in Middlebrook $7 \mathrm{H} 9$ broth supplemented with $10 \%$ oleic albumin dextrose catalase (OADC), $0.2 \%$ glycerol, and $0.05 \%$ Tween 80 (MB broth). Bacilli in the mid-log growth phase (7-8 days old, $\left.\mathrm{OD}_{600}=0.5-0.6\right)$ were harvested by centrifugation and resuspended (20 mg wet wt $/ \mathrm{mL}$ ) in $\mathrm{MB}$ broth containing $15 \%$ glycerol as a cryopreservative. The bacterial suspension was stored in aliquots at $-80{ }^{\circ} \mathrm{C}$. Viable counts (colonyforming units, cfu) were determined by plating the bacteria ( 50 $\mu \mathrm{L}$, diluted in $\mathrm{MB}$ broth) on $\mathrm{MB} 7 \mathrm{H} 11$ agar supplemented with $10 \%$ OADC and $0.5 \%$ glycerol (MB agar) and incubating (37 ${ }^{\circ} \mathrm{C}$ ) until countable colonies appeared (3-4 weeks).

Preparation of S006-830 Racemate and Enantiomers. S006-830 racemate was synthesized as described earlier ${ }^{4}$ (Supporting Information, Figure S1). The enantiomers were purified by supercritical fluid chromatography on a chiral column (Chiralcel OJ-H column, Daicel Corp., Japan). The optimized protocol comprised a mobile phase of $0.5 \%$ isopropanol in methanol, with a flow rate of $2.5 \mathrm{~mL} / \mathrm{min}$, temperature of $35^{\circ} \mathrm{C}$, and detection wavelength of $233 \mathrm{~nm}$.

Assay for Activity against Mtb. Activity against Bacilli in Broth Culture. Stock solutions of drugs and test compounds were prepared in dimethyl sulfoxide and stored at $-20{ }^{\circ} \mathrm{C}$. For determination of in vitro activity, a stock of $\mathrm{Mtb}$ was thawed and inoculated in the assay tubes $\left(\sim 5 \times 10^{5} \mathrm{cfu} / \mathrm{mL}\right.$ of $\mathrm{MB}$ broth/tube) containing drug or the test compound. Drug-free tubes served as controls. All tubes were incubated $\left(37^{\circ} \mathrm{C}\right)$ up to 7 days. For cfu determinations, serial 10-fold dilutions of bacilli were spread on $\mathrm{MB}$ agar plates (50 $\mu \mathrm{L} /$ plate $)$ and incubated for 3-4 weeks. Minimum inhibitory concentration (MIC) was the lowest concentration of a drug/compound that inhibited $\geq 99 \%$ of the Mtb growth (in terms of cfu) seen in drug-free tubes. Minimum bactericidal concentration (MBC) was the lowest concentration of a compound that killed $\geq 90 \%$ of the bacilli in initial inoculums.

Activity against Intracellular Bacilli. The study protocol was approved by CDRI's Animal Ethics Committee. Mouse bone marrow-derived macrophages (BMDMs) were prepared as follows. Bone marrow cells from femurs and tibia of Swiss mice were harvested in Dulbecco's modified Eagle's medium (DMEM) by flushing out the marrow using a syringe. Cells were collected by centrifugation $(1000 \mathrm{~g}, 15 \mathrm{~min})$ and resuspended in "complete medium" (DMEM with 10\% fetal bovine serum, $15 \%$ culture supernatant of L929 cells, and $1 \%$ nonessential amino acids). After counting, the cells $\left(2 \times 10^{6} /\right.$ $\mathrm{mL}$ ) were dispensed in 48-well culture plates and incubated for 5 days in a $\mathrm{CO}_{2}$ incubator $\left(37^{\circ} \mathrm{C}, 5 \% \mathrm{CO}_{2}\right)$ for adherence and maturation. Approximately $6 \%$ of the input cells got adhered and $>95 \%$ of the adherent cells showed positivity for the macrophage marker CD11b, as determined by flow cytometry.

For intracellular (ex vivo) killing experiments, thawed Mtb stock was diluted in complete medium without antibiotics. Aggregated bacilli were dispersed by a short pulse (10 s) of sonication, which did not affect their viability (ascertained by cfu counts). The matured BMDM were infected $\left(3 \mathrm{~h}, 37^{\circ} \mathrm{C}\right.$, $5 \% \mathrm{CO}_{2}$ ) with $\mathrm{Mtb}$ using a multiplicity of infection (MOI; bacilli/macrophage) of 5 . Later, the macrophage monolayer was washed extensively with DMEM to remove extracellular bacilli. Drugs and test compounds (diluted in complete medium) or medium alone were dispensed in respective wells $\left(350 \mu \mathrm{L} /\right.$ well), and plates were incubated in a $\mathrm{CO}_{2}$ incubator for further 5 days. For intracellular cfu determinations, the cells were lysed with saponin $(0.1 \%, 100 \mu \mathrm{L} /$ well, $15 \mathrm{~min})$ and the lysates, after diluting in complete medium, were plated on $\mathrm{MB}$ agar and incubated for 3-4 weeks.

Assay for Drug-Drug Interactions. Interactions between frontline TB drugs and test compound were determined by two-drug checkerboard method, ${ }^{36}$ with some modifications. Briefly, in a 96-well " $U$ " bottom plate, the test compound (in $\mathrm{MB}$ broth) was serially diluted vertically and TB drug was diluted horizontally so as to obtain their various combinations. The bottom row (row $\mathrm{H}$ ) of the plate contained dilutions of drug alone, and column 11 contained dilutions of compound alone. Column 12 was used for drug-free culture (control). Final volume per well was $100 \mu \mathrm{L}$. Mid-log phase culture $\left(\mathrm{OD}_{600}=0.1\right.$, equivalent to $\sim 10^{7} \mathrm{bacilli} / \mathrm{mL}$ ) of Mtb was added to the plate $(100 \mu \mathrm{L} /$ well $)$. All assay plates were incubated in the $\mathrm{CO}_{2}$ incubator for 2-3 weeks before reading for macroscopic bacterial growth. MIC was the lowest concentration of a drug/compound that produced no visible growth of the bacilli in inoculums (by this criteria, the MIC became equivalent to MBC). Fractional inhibitory concentration (FIC) and fractional inhibitory concentration index (FICI) were calculated as follows: FIC = MIC of a drug in combination/ MIC alone; FICI = FIC of drug A + FIC of drug B. FICI values of $\leq 0.5$ indicate synergistic activity, of $\geq 4.0$ indicate antagonistic activity, and in between $\leq 4.0$ and $\geq 0.5$ indicate an additive interaction. ${ }^{37}$

Assay for Time-Kill Kinetics. Kill kinetics was determined by the cfu assay. ${ }^{36}$ Briefly, dilutions of compound alone or in combination with drugs were prepared in $\mathrm{MB}$ broth $(4.5 \mathrm{~mL}$ / tube). Mtb culture in $\mathrm{MB}$ broth was added $(0.5 \mathrm{~mL} /$ tube, final count $\left.=5 \times 10^{5} \mathrm{cfu} / \mathrm{mL}\right)$, and tubes were incubated $\left(37^{\circ} \mathrm{C}\right)$ in a shaker incubator. At different time points $(0,2,4,6$, and 8 days), $50 \mu \mathrm{L}$ of 10 -fold dilutions of Mtb suspension was plated on $\mathrm{MB}$ agar and incubated until countable colonies appeared (3-4 weeks).

Generation of S-S006-830-Resistant Mtb and Isolation of Subcellular Proteins. Mtb resistant to the test compound was generated by plating wild-type bacilli on $\mathrm{MB}$ agar containing $4 \times$ and $8 \times$ MIC of the compound and incubating for 4 weeks. Visible colonies were picked from $4 \times$ MIC plate and subcultured in $\mathrm{MB}$ broth containing $4 \times \mathrm{MIC}$ of the compound. The compound-resistant bacilli prepared in this manner did not show cross resistance to the frontline TB drugs rifampicin (RIF), isoniazid (INH), and ethambutol (EMB), as determined by the proportion assay. ${ }^{38}$

Subcellular protein fractions of the wild-type or compoundresistant $\mathrm{Mtb}$ were prepared according to a previously described method. ${ }^{21}$ In brief, a suspension of $\mathrm{Mtb}$ in the "sonication buffer" (50 mM Tris, $10 \mathrm{mM} \mathrm{MgCl}, 1 \mathrm{mM}$ EGTA, $1 \mathrm{mM}$ PMSF, and $1 \mathrm{mM} \mathrm{NaN}_{3}, \mathrm{pH} 7.4$ ) was pulse-sonicated for $20 \mathrm{~min}$. The sonicate was centrifuged at $23000 \mathrm{~g}$ for $20 \mathrm{~min}$ to settle the cell wall debris and unbroken bacilli. The supernatant was recentrifuged at $150000 \mathrm{~g}$ for $90 \mathrm{~min}$ to obtain the cell membrane (sediment) and cytosol (supernatant). Protein was estimated by a modified Lowry method ${ }^{39}$ and both fractions, in aliquots, were stored at $-20{ }^{\circ} \mathrm{C}$.

Identification of the Drug Target(s) by Chemical Proteomics. Affinity Chromatography Using Matrix-Bound 
Test Compound. A steroid drug compound (SDC) immobilization method that works on the concept of the Mannich condensation reaction ${ }^{40}$ was used and the kit manufacturer's protocol was followed. In this formaldehyde-mediated reaction, the compound gets covalently bound to DADPA through condensation of its active hydrogen. In brief, $4 \mathrm{~mL}$ of beads (of $50 \%$ slurry) covalently linked with DADPA was taken in a 15 $\mathrm{mL}$ "V" bottom tube and centrifuged $(700 \mathrm{~g}, 2 \mathrm{~min})$. After removing the supernatant, the resin was washed ( 5 times) with $4 \mathrm{~mL}$ of $50 \%$ ethanol/SDC coupling buffer, and $2.5 \mathrm{~mL}(5 \mathrm{mg} /$ $\mathrm{mL}$ ) of test compound dissolved in the coupling buffer was added to the resin. To it, $200 \mu \mathrm{L}$ of coupling reagent was also added. The tube was sealed and incubated $\left(37^{\circ} \mathrm{C}, 24 \mathrm{~h}\right)$ with endover mixing. The reaction buffer was removed by centrifugation and the resin was washed (10 times) with 1:1 mixture of SDC wash buffer and ethanol. The affinity matrix thus prepared was stored at $4{ }^{\circ} \mathrm{C}$.

In a $2 \mathrm{~mL}$ microcentrifuge tube, $200 \mu \mathrm{L}$ of affinity matrix was equilibrated with the sonication buffer containing 4\% CHAPS. Working dilution of $\mathrm{Mtb}$ membrane $(2 \mathrm{mg}$ protein $/ \mathrm{mL}$ ) was also made in the same buffer, and $1 \mathrm{~mL}$ of it was mixed with the resin and incubated $\left(4{ }^{\circ} \mathrm{C}\right.$, overnight) with endover mixing. Later, the resin was washed (4 times) with sonication buffer containing $0.06 \%$ CHAPS to remove the unbound or loosely bound proteins. To ascertain that all unbound proteins were removed, the protein content of washes as well as resin-bound proteins were monitored by SDS-PAGE using $12 \%$ gel.

Protein Identification by Two-Dimensional Gel Electrophoresis (2-DE) Followed by Mass Spectrometry. For 2-DE, ${ }^{41}$ $150 \mu \mathrm{L}$ of resin-bound proteins (slurry) was solubilized in 150 $\mu \mathrm{L}$ of sample solubilization medium ( $7 \mathrm{M}$ urea, $2 \mathrm{M}$ thiourea, 4\% CHAPS, $0.5 \%$ carrier ampholytes, $1 \%$ dithiothreitol, $10 \%$ isopropanol, and 5\% glycerol). After centrifugation (12000 $\mathrm{rpm}, 10 \mathrm{~min}$ ), $150 \mu \mathrm{L}$ of clear supernatant was applied to an IPG strip ( $\mathrm{pH} 4-7$ ) and left overnight for rehydration. Isoelectric focusing (IEF) of the rehydrated strips was performed in a Protean IEF Cell (Bio-Rad) using a three-step gradient, with the following parameters: maximum voltage, 2500; maximum current, $50 \mu \mathrm{A} /$ strip; total volt hour, 10000 . Later, the strips were equilibrated (for $15 \mathrm{~min}$ each) in solutions "A" (0.05 M Tris- $\mathrm{HCl}, \mathrm{pH} 8.8$, containing $6 \mathrm{M}$ urea, $30 \%$ glycerol, $2 \%$ SDS, and 1\% DTT) and "B" (solution A without DTT, but with $4 \%$ iodoacetamide and $0.005 \%$ bromophenol blue). The strips were loaded on top of SDSpolyacrylamide gel slabs ( $12 \%$ gel) and electrophoresis was performed at a constant current of $15 \mathrm{~mA}$. Gels were stained with Coomassie Blue G250 and destained with water. Gel imaging was performed on Gel Doc EZ imaging system (BioRad).

Protein spots in gel were punched out and processed for identification by LC-MS-MS analysis. ${ }^{42}$ In brief, gel plugs were destained and washed (in $25 \mathrm{mM}$ ammonium bicarbonate in 50:50 acetonitrile/water), vacuum-dried, and trypsin-digested (12.5 mg/mL trypsin, $25 \mathrm{mM}$ ammonium bicarbonate, overnight at $37^{\circ} \mathrm{C}$ ). The tryptic peptides were extracted with acetonitrile containing $1 \%$ trifluoroacetic acid $(20 \mathrm{~min}, 2$ cycles). The extracts were dried by rotary evaporation and analyzed by electrospray ionization mass spectrometry (ESI MS) using Shimadzu Prominence nano HPLC system (Shimadzu) coupled to a 5600 Triple TOF mass spectrometer (AB Sciex). Peptides were loaded onto an Agilent Zorbax 300SB-C18 3.5 $\mu \mathrm{M}$ column and separated with a linear gradient of water/acetonitrile/ $0.1 \%$ formic acid. Spectra were analyzed to identify proteins using the Mascot sequence matching software (Matrix Science) and MSPnr100 database.

Identification of Drug Target(s) by Comparative Proteomics. Aliquots of $200 \mu \mathrm{g}$ lyophilized membrane protein of $\mathrm{Mtb}$ (wild-type or compound-resistant) were solubilized in $175 \mu \mathrm{L}$ of solubilization medium and subjected to 2-DE, as described above. Spots of interest were picked, and the corresponding proteins were identified by LC MS-MS, as described above.

Validation of the Identified Target (FabG4). MIC Assay Using Mtb Overexpressing the Target Protein. The fabG4 gene of Mtb was amplified using the primer pair FP $5^{\prime}$ CGAGGATCCGTGGCTCCCAAGCGTTCGTC- $3^{\prime}$ and RP 5'-CCCAAGCTTTCACGCGCCGATCATGGCC-3' containing BamHI and HindIII sites (highlighted in bold letters) as described $^{18}$ and ligated into shuttle vector pMV261 and transformed into E. coli DH5 $\alpha$. The fabG4 recombinant plasmid and vector control pMV261 were electroporated (ECM 399 Electroporation System, BTX from VWR) into competent cells of $\mathrm{Mtb}{ }^{43}$ The transformed cells were plated on $\mathrm{MB}$ agar containing kanamycin ( $\mathrm{KM}, 30 \mu \mathrm{g} / \mathrm{mL}$ ). The transformants were grown in $\mathrm{MB}$ broth containing $30 \mu \mathrm{g} / \mathrm{mL}$ of KM.

To confirm the overexpression of FabG4, whole cell lysates of wild-type Mtb, Mtb::pMV261-fabG4 and Mtb::pMV261 were resolved by 2-DE and FabG4 protein was identified by ESI MS-MS, as per the protocol described above.

The sensitivity of Mtb strains (wild type, wild type::pMV261, and wild type Mtb::pMV261-fabG4) for the test compound and anti-TB drugs was determined by the MIC assay (described above).

Assay for Cell Wall Mycolic Acids. To study the effect of the compound on mycolic acid biosynthesis, a previously described method was used. ${ }^{44}$ Drug dilutions were incubated $\left(37^{\circ} \mathrm{C}\right.$ for $15 \mathrm{~h})$ with log-phase culture of $\mathrm{Mtb}\left(\mathrm{OD}_{600} \sim 1.5\right)$ in $15 \mathrm{~mL}$ screw-capped culture tubes. Later, $1 \mu \mathrm{Ci} / \mathrm{mL}$ of $\left[{ }^{14} \mathrm{C}\right]$ acetate $(56 \mathrm{mCi} / \mathrm{mmol})$ was added to each tube. Following incubation for another $8 \mathrm{~h}$ at $37{ }^{\circ} \mathrm{C}$, the $\left[{ }^{14} \mathrm{C}\right]$ labeled cells were harvested, washed with phosphate-buffered saline (PBS), and sterilized by autoclaving. The lipids in cell sediments were hydrolyzed by adding $2 \mathrm{~mL}$ of tetra- $n$-butylammonium hydroxide and incubating overnight at $100{ }^{\circ} \mathrm{C}$. Fatty acids were esterified by adding $4 \mathrm{~mL}$ of $\mathrm{CH}_{2} \mathrm{Cl}_{2}, 300 \mu \mathrm{L}$ of $\mathrm{CH}_{3} \mathrm{I}$, and $2 \mathrm{~mL}$ of distilled water and mixing (at room temperature, RT) for $1 \mathrm{~h}$. After centrifugation, the upper phase was discarded and the samples were washed twice with distilled water. The lower phase was dried and resuspended in $3 \mathrm{~mL}$ of diethylether. After centrifugation, the organic phase was dried and lipids were resuspended in $200 \mu \mathrm{L}$ of $\mathrm{CH}_{2} \mathrm{Cl}_{2}$. Equal counts were loaded on a silica gel $60 \mathrm{~F}_{254}$ thin-layer chromatography (TLC) plate and resolved using hexane/ethyl acetate (19:1, v/v, 2 runs). To detect radiolabeled mycolic acid methyl esters (MAMEs), TLC plates were exposed to a phosphor screen (Bio-Rad) and visualized using a Typhoon Trio imager (GE Healthcare). Densitometry was performed on scanned phosphor screen images using the ImageJ image analysis tool. ${ }^{45}$ Arbitrary numbers were obtained from each experimental condition with reference to the corresponding untreated control. Further, the percentage of the value measured in untreated control was calculated and presented as histograms.

Assay for Inhibition of Biofilm Formation. Biofilm inhibition assay was performed as described, ${ }^{16}$ with some modifications. In brief, Mtb was grown in MB broth until the 
$\mathrm{OD}_{600}$ reached $0.8-1.0$ ( $\sim 1$ week). The culture was centrifuged (8000 rpm, $15 \mathrm{~min}$ ), and the pellet washed with PBS. Final sediment was resuspended in Sauton's liquid medium (without Tween). Drug dilutions, prepared in Sauton's medium, were dispensed in a 12-well culture plate $(4 \mathrm{~mL} /$ well $)$. Mtb culture (final $\mathrm{OD}_{600}=0.1$ ) was also dispensed in the same plate $(0.5$ $\mathrm{mL} /$ well). Wells without drug (with vehicle) served as control. The plate was sealed with parafilm and incubated for 5 weeks in a $\mathrm{CO}_{2}$ incubator. Formation of biofilm was monitored visually.

Determination of Crystal Structure of S-S006-830 and Computational Studies. Crystal Structure Determination. Single crystals of the pure enantiomer were grown from methanol solvent by slow evaporation method at RT. Singlecrystal X-ray diffraction studies were performed on a Bruker D8 Venture diffractometer using the $\mathrm{Cu} \mathrm{K} \alpha$ radiation. Full X-ray crystallographic data collection and structure refinement details are provided in the Supporting Information, Table S2. Crystallographic data have been deposited with the Cambridge Crystallographic Data Centre (CCDC deposition number 1543553).

Molecular Electrostatic Potential Surface Calculations. Geometric optimization of S-S006-830 was performed using density functional theory at M062X/6-311++g (d,p) level of the theory. ${ }^{46}$ Local maxima and minima on the molecular electrostatic potential mapped on the electron density isosurface (isovalue $=0.002 \mathrm{e} / \mathrm{bohr}^{3}$ ) were determined using Multiwfn software (version 3.3.9). ${ }^{47}$ Electrophilic and nucleophilic sites on the molecule were determined using the method described. $^{48}$

Molecular Docking. The crystal structure of the Mtb FabG4-NAD ${ }^{+}$-hexanoyl-CoA complex was retrieved from the Protein Data Bank (PDB ID: 3VIU). The FabG4 structure was corrected for missing atomic data, alternate locations, breaks (missing loops), protonation site adjustment, missing $\mathrm{H}$ atom addition, and charge neutralization before performing modeling studies using MOE software suite. ${ }^{49}$ This was followed by sequential minimization of atoms belonging to solvent, side chain, backbone, receptor, and finally the whole system.

Probable active sites suitable for ligand binding on the FabG4 were identified by the Alfa Shapes method using the MOE site finder module. Active sites were ranked based on "propensity for ligand binding (PLB)" score determined on the basis of size, accessibility, and exposure to solvent molecules. Molecular docking studies were performed using the induced-fit model, using the MOE dock module. Initial poses (total 30 poses/ molecule) were generated using the triangle matcher method and scored using the London $\mathrm{dG}$ scoring function. These poses were subject to rescoring, and top five poses were selected using an induced-fit model using the generalized Born volume integral/weighted surface area (GBVI/WSA) dG scoring function. ${ }^{50}$

Statistical Analysis. Statistical analyses were performed using Microsoft Excel 2010 and GraphPad prism. Significance level $(p<0.05)$ of differences was determined by two-tailed Student's $t$-test.

\section{ASSOCIATED CONTENT}

\section{S Supporting Information}

The Supporting Information is available free of charge on the ACS Publications website at DOI: 10.1021/acsomega.7b01281.
Materials and software (Table S1); X-ray crystallographic data collection and structure refinement details (Table S2 and text); drug sensitivity profiles of wild-type and $S$ S006-830-resistant Mtb (Table S3); proteins overexpressed in the S-S006-830-resistant Mtb (Table S4); drug sensitivity profiles of the Mtb constructs (Table S5); data on molecular docking (Tables S6-S9); synthetic scheme for S006-830 (Figure S1); structures of DADPA-activated and S-S006-830-coupled agarose beads (Figure S2); SDS-PAGE of Mtb membrane proteins that were bound or did not bind to the $S$ S006-830 affinity beads (Figure S3); membrane subproteome of the wild-type and S-S006-830-resistant Mtb (Figure S4); 2-DE images of the cell lysates of Mtb::pMV261-fabG4, Mtb::pMV261, and wild-type Mtb (Figure S5); inhibition of Mtb biofilm by S-S006830 (Figure S6); images of docking of S006-830 enantiomers on Mtb FabG4 (Figures S7-S9); supporting references (PDF)

\section{Accession Codes}

Crystallographic data for S-S006-830 have been deposited with the Cambridge Crystallographic Data Centre (CCDC deposition number 1543553). The crystal structure of the Mtb FabG4-NAD ${ }^{+}$-hexanoyl-CoA complex was retrieved from the Protein Data Bank (PDB ID: 3VIU).

\section{AUTHOR INFORMATION}

\section{Corresponding Authors}

*E-mail: vinita_chaturvedi@cdri.res.in (V.C.).

*E-mail: tejender.thakur@cdri.res.in (T.S.T.).

*E-mail: ssinha@sgpgi.ac.in (S.S.).

ORCID

Sudhir Sinha: 0000-0003-3149-1116

\section{Author Contributions}

S.S. planned and designed the study. S.S., T.S.T., V.C., A.K.D., and P.S. finalized the study protocols. P.S., S.K.K., V.K.M., B.K.M., and H.A. performed the experiments. P.S., V.C. and S.S. analyzed the data. S.S., T.S.T., and P.S. wrote the paper.

\section{Notes}

The authors declare no competing financial interest.

\section{ACKNOWLEDGMENTS}

This work was partially supported by the Open Source Drug Discovery (OSDD) program of CSIR India, which was also instrumental in bulk procurement of S006-830 through a chemistry contract. P.S. is indebted to UGC India for his Research Fellowship. The authors thank Meraj Zaidi, Sunil Gupta, and Ankur Omer for their help with various assays. This paper is CDRI Communication Number-9571.

\section{REFERENCES}

(1) World Health Organization. Global Tuberculosis Report, 2016. http: / / apps.who.int/iris / bitstream/10665/250441/1/ 9789241565394-eng.pdf?ua=1 (accessed Feb 2, 2017).

(2) Parai, M. K.; Panda, G.; Chaturvedi, V.; Manju, Y. K.; Sinha, S. Thiophene containing triaryl methanes as antitubercular agents. Bioorg. Med. Chem. Lett. 2008, 18, 289-292.

(3) Kashyap, V. Kr.; Gupta, R. Kr.; Shrivastava, R.; Srivastava, B. S.; Srivastava, R.; Parai, M. K.; Singh, P.; Bera, S.; Panda, G. In vivo activity of thiophene-containing trisubstituted methanes against acute and persistent infection of non-tubercular Mycobacterium fortuitum in a 
murine infection model. J. Antimicrob. Chemother. 2012, 67, 11881197.

(4) Singh, P.; Manna, S. K.; Jana, A. K.; Saha, T.; Mishra, P.; Bera, S.; Parai, M. K.; Kumar, M. S. L.; Mondal, S.; Trivedi, P.; Chaturvedi, V.; Singh, S.; Sinha, S.; Panda, G. Thiophene containing trisubstituted methanes [TRSMs] as identified lead against Mycobacterium tuberculosis. Eur. J. Med. Chem. 2015, 95, 357-368.

(5) Singh, P.; Saha, T.; Mishra, P.; Parai, M. K.; Ireddy, S.; Kumar, M. S. L.; Krishna, S.; Kumar, S. K.; Chaturvedi, V.; Sinha, S.; Siddiqi, M. I.; Panda, G. Additional synthesis on thiophene containing trisubstituted methanes (TRSMs) as inhibitors of Mycobacterium tuberculosis and 3D-QSAR studies. SAR QSAR Environ. Res. 2016, 27, 883-909.

(6) Singh, Y.; Hidau, M. K.; Misra, A.; Kushwaha, H. N.; Tiwari, A.; Sharma, A. K.; Singh, S. K. UFLC method development and validation of a novel triethylamine containing thiophene S006-830-an antitubercular molecule and its application to pharmacokinetic and bioavailability studies in SD rats. Drug Test. Anal. 2015, 7, 721-726.

(7) Hidau, M. K.; Singh, Y.; Shahi, S.; Mounika, P.; Singh, S. K. LCMS/MS Assay for Quantification of a Novel Antitubercular Molecule S006-830: Pharmacokinetic and plasma protein binding studies in rats. Curr. Pharm. Anal. 2015, 11, 35-42.

(8) Hidau, M. K.; Singh, Y.; Singh, S. K. Intestinal permeability, role of P-glycoprotein in intestinal absorption of triethylamine containing thiophene S006-830. Int. J. Pharmacokinet. 2017, 11, 35-42.

(9) Hutt, A. J.; O’ Grady, J. Drug chirality: a consideration of the significance of the stereochemistry of antimicrobial agent. J. Antimicrob. Chemother. 1996, 37, 7-32.

(10) Hayakawa, I.; Atarashi, S.; Yokohama, S.; Imamura, M.; Sakano, K. I.; Furukawa, M. Synthesis and antibacterial activities of optically active ofloxacin. Antimicrob. Agents Chemother. 1986, 29, 163-164.

(11) Gurumurthy, M.; Mukherjee, T.; Dowd, C. S.; Singh, R.; Niyomrattanakit, P.; Tay, J. A.; Nayyar, A.; Lee, Y. S.; Cherian, J.; Boshoff, H. I.; Dick, T.; Barry, C. E.; Manjunatha, U. H. Substrate specificity of the deazaflavin-dependent nitroreductase from $\mathrm{Myco}$ bacterium tuberculosis responsible for the bioreductive activation of bicyclic nitroimidazoles. FEBS J. 2012, 279, 113-125.

(12) Koul, A.; Dendouga, N.; Vergauwen, K.; Molenberghs, B.; Vranckx, L.; Willebrords, R.; Ristic, Z.; Lill, H.; Dorange, I.; Guillemont, J.; Bald, D.; Andries, K. Diarylquinolines target subunit c of mycobacterial ATP synthase. Nat. Chem. Biol. 2007, 3, 323-324.

(13) Makarov, V.; Manina, G.; Mikusova, K.; Möllmann, U.; Ryabova, O.; Saint-Joanis, B.; Dhar, N.; Pasca, M. R.; Buroni, S.; Lucarelli, A. P.; Milano, A.; et al. Benzothiazinones kill Mycobacterium tuberculosis by blocking arabinan synthesis. Science 2009, 324, 801804.

(14) Rix, U.; Superti-Furga, G. Target profiling of small molecules by chemical proteomics. Nat. Chem. Biol. 2009, 5, 616-624.

(15) Jankute, M.; Cox, J. A.; Harrison, J.; Besra, G. S. Assembly of the mycobacterial cell wall. Annu. Rev. Microbiol. 2015, 69, 405-423.

(16) Ojha, A. K.; Baughn, A. D.; Sambandan, D.; Hsu, T.; Trivelli, X.; Guerardel, Y.; Alahari, A.; Kremer, L.; Jacobs, W. R., Jr.; Hatfull, G. F. Growth of Mycobacterium tuberculosis biofilms containing free mycolic acids and harbouring drug-tolerant bacteria. Mol. Microbiol. 2008, 69, 164-174.

(17) Gygli, S. M.; Borrell, S.; Trauner, A.; Gagneux, S. Antimicrobial resistance in Mycobacterium tuberculosis: mechanistic and evolutionary perspectives. FEMS Microbiol. Rev. 2017, 41, 354-373.

(18) Dutta, D.; Bhattacharyya, S.; Mukherjee, S.; Saha, B.; Das, A. K. Crystal structure of FabG4 from Mycobacterium tuberculosis reveals the importance of C-terminal residues in ketoreductase activity. J. Struct. Biol. 2011, 174, 147-155.

(19) Kerns, P. W.; Ackhart, D. F.; Basaraba, R. J.; Leid, J. G.; Shirtliff, M. E. Mycobacterium tuberculosis pellicles express unique proteins recognized by the host humoral response. Pathog. Dis. 2014, 70, 347358.

(20) Parsons, S.; Flack, H. D.; Wagner, T. Use of intensity quotients and differences in absolute structure refinement. Acta Crystallogr., Sect. B: Struct. Sci., Cryst. Eng. Mater. 2013, 69, 249-259.
(21) Sinha, S.; Kosalai, K.; Arora, S.; Namane, A.; Sharma, P.; Gaikwad, A. N.; Brodin, P.; Cole, S. T. Immunogenic membraneassociated proteins of Mycobacterium tuberculosis revealed by proteomics. Microbiology 2005, 151, 2411-2419.

(22) Lew, J. M.; Mao, C.; Shukla, M.; Warren, A.; Will, R.; Kuznetsov, D.; Xenarios, I.; Robertson, B. D.; Gordon, S. V.; Schnappinger, D.; Cole, S. T.; et al. Database resources for the tuberculosis community. Tuberculosis 2013, 93, 12-17.

(23) Sritharan, M. Iron homeostasis in Mycobacterium tuberculosis: mechanistic insights into siderophore-mediated iron uptake. $J$. Bacteriol. 2016, 198, 2399-2409.

(24) Wilson, D. N.; Nierhaus, K. H. The weird and wonderful world of bacterial ribosome regulation. Crit. Rev. Biochem. Mol. Biol. 2007, 42, $187-219$.

(25) Wang, M.; Weiss, M.; Simonovic, M.; Haertinger, G.; Schrimpf, S. P.; Hengartner, M. O.; von Mering, C. PaxDb, a database of protein abundance averages across all three domains of life. Mol. Cell. Proteomics 2012, 11, 492-500.

(26) Pandey, R.; Rodriguez, G. M. A ferritin mutant of Mycobacterium tuberculosis is highly susceptible to killing by antibiotics and is unable to establish a chronic infection in mice. Infect. Immun. 2012, 80, 36503659.

(27) Sharma, D.; Lata, M.; Faheem, M.; Khan, A. U.; Joshi, B.; Venkatesan, K.; Shukla, S.; Bisht, D. M. tuberculosis ferritin (Rv3841): Potential involvement in Amikacin (AK) \& Kanamycin (KM) resistance. Biochem. Biophys. Res. Commun. 2016, 478, 908-912.

(28) Vilchèze, C.; Jacobs, W. R., Jr. The Mechanism of isoniazid killing: Clarity through the scope of genetics. Annu. Rev. Microbiol. 2007, 61, 35-50.

(29) Cole, S. T.; Eiglmeier, K.; Parkhill, J.; James, K. D.; et al. Massive gene decay in the leprosy bacillus. Nature 2001, 409, 1007-1011.

(30) Kikuchi, S.; Kusaka, T. New malonyl-CoA-dependent fatty acid elongation system in Mycobacterium smegmatis. J. Biochem. 1982, 92, 839-844.

(31) Gurvitz, A. The essential mycobacterial genes, fabG1 and fabG4, encode 3-oxoacyl-thioester reductases that are functional in yeast mitochondrial fatty acid synthase type 2. Mol. Genet. Genomics 2009, 282, 407-416.

(32) Marrakchi, H.; Ducasse, S.; Labesse, G.; Montrozier, H.; Margeat, E.; Emorine, L.; Charpentier, X.; Daffé, M.; Quémard, A. MabA (FabG1), a Mycobacterium tuberculosis protein involved in the long-chain fatty acid elongation system FAS-II. Microbiology 2002, 148, 951-960.

(33) Bacon, J.; Alderwick, L. J.; Allnutt, J. A.; Gabasova, E.; Watson, R.; Hatch, K. A.; Clark, S. O.; Jeeves, R. E.; Marriott, A.; Rayner, E.; Tolley, H.; et al. Non-replicating Mycobacterium tuberculosis elicits a reduced infectivity profile with corresponding modifications to the cell wall and extracellular matrix. PLoS One 2014, 9, No. e87329.

(34) Kumar, S. K.; Singh, P.; Sinha, S. Naturally produced opsonizing antibodies restrict the survival of Mycobacterium tuberculosis in human macrophages by augmenting phagosome maturation. Open Biol. 2015, 5, No. 150171.

(35) Medina-Franco, J. L.; Giulianotti, M. A.; Welmaker, G. S.; Houghten, R. A. Shifting from the single to the multitarget paradigm in drug discovery. Drug Discovery Today 2013, 18, 495-501.

(36) Reddy, V. M.; Einck, L.; Andries, K.; Nacy, C. A. In vitro interactions between new antitubercular drug candidates SQ109 and TMC207. Antimicrob. Agents Chemother. 2010, 54, 2840-2846.

(37) Odds, F. C. Synergy, antagonism, and what the chequerboard puts between them. J. Antimicrob. Chemother. 2003, 52, 1.

(38) McClatchy, J. K. Susceptibility testing of mycobacteria. Lab. Med. 1978, 9, 47-52.

(39) Markwell, M. A. K.; Haas, S. M.; Bieber, L. L.; Tolbert, N. E. A modification of the Lowry procedure to simplify protein determination in membrane and lipoprotein samples. Anal. Biochem. 1978, 87, 206210.

(40) Blicke, F. F. Organic Reactions; John Wiley and Sons Inc.: New York, N.Y., 1942; Vol. 1, pp 303-341. 
(41) Aggarwal, A.; Gupta, R.; Negi, V. S.; Rajasekhar, L.; Misra, R.; Singh, P.; Chaturvedi, V.; Sinha, S. Urinary haptoglobin, alpha-1 antichymotrypsin and retinol binding protein identified by proteomics as potential biomarkers for lupus nephritis. Clin. Exp. Immunol. 2017, $188,254-262$.

(42) Bringans, S.; Eriksen, S.; Kendrick, T.; Gopalakrishnakone, P.; Livk, A.; Lock, R.; Lipscombe, R. Proteomic analysis of the venom of Heterometrus longimanus (Asian black scorpion). Proteomics 2008, 8, 1081-1096.

(43) Goude, R.; Parish, T. Electroporation of mycobacteria. J. Visualized Exp. 2008, 15, 761.

(44) Wilson, R.; Kumar, P.; Parashar, V.; Vilchèze, C.; VeyronChurlet, R.; Freundlich, J. S.; Barnes, S. W.; Walker, J. R.; Szymonifka, M. J.; Marchiano, E.; Shenai, S.; et al. Antituberculosis thiophenes define a requirement for Pks13 in mycolic acid biosynthesis. Nat. Chem. Biol. 2013, 9, 499-506.

(45) Abramoff, M. D.; Magelhaes, P. J.; Ram, S. J. Image Processing with Imagej. Biophotonics Int. 2004, 11, 36-42.

(46) Frisch, M. J.; Trucks, G. W.; Schlegel, H. B.; Scuseria, G. E.; Robb, M. A.; Cheeseman, J. R.; Scalmani, G.; Barone, V.; Mennucci, B.; Petersson, G. A.; et al. Gaussian 09 Program; Gaussian, Inc.: Wallingford, CT, 2011.

(47) Lu, T.; Chen, F. Quantitative analysis of molecular surface based on improved Marching Tetrahedra algorithm. J. Mol. Graphics Modell. 2012, 38, 314-323.

(48) Musumeci, D.; Hunter, C. A.; Prohens, R.; Scuderi, S.; McCabe, J. F. Virtual cocrystal screening. Chem. Sci. 2011, 2, 883-890.

(49) Molecular Operating Environment (MOE) 2016.08; Chemical Computing Group, Inc.: Montreal, QC, Canada, 2016.

(50) Labute, P. The generalized Born/volume integral implicit solvent model: estimation of the free energy of hydration using London dispersion instead of atomic surface area. J. Comput. Chem. 2008, 29, 1693-1698. 